Supplement of Biogeosciences Discuss., 12, 3025-3055, 2015

http://www.biogeosciences-discuss.net/12/3025/2015/

doi:10.5194/bgd-12-3025-2015-supplement

(C) Author(s) 2015. CC Attribution 3.0 License.

(c) (1)

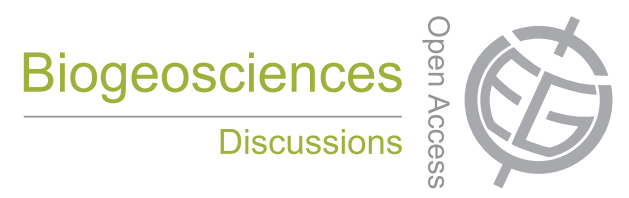

Supplement of

Growth response of temperate mountain grasslands to inter-annual variations of snow cover duration

\title{
P. Choler
}

Correspondence to: P. Choler (philippe.choler@ujf-grenoble.fr) 

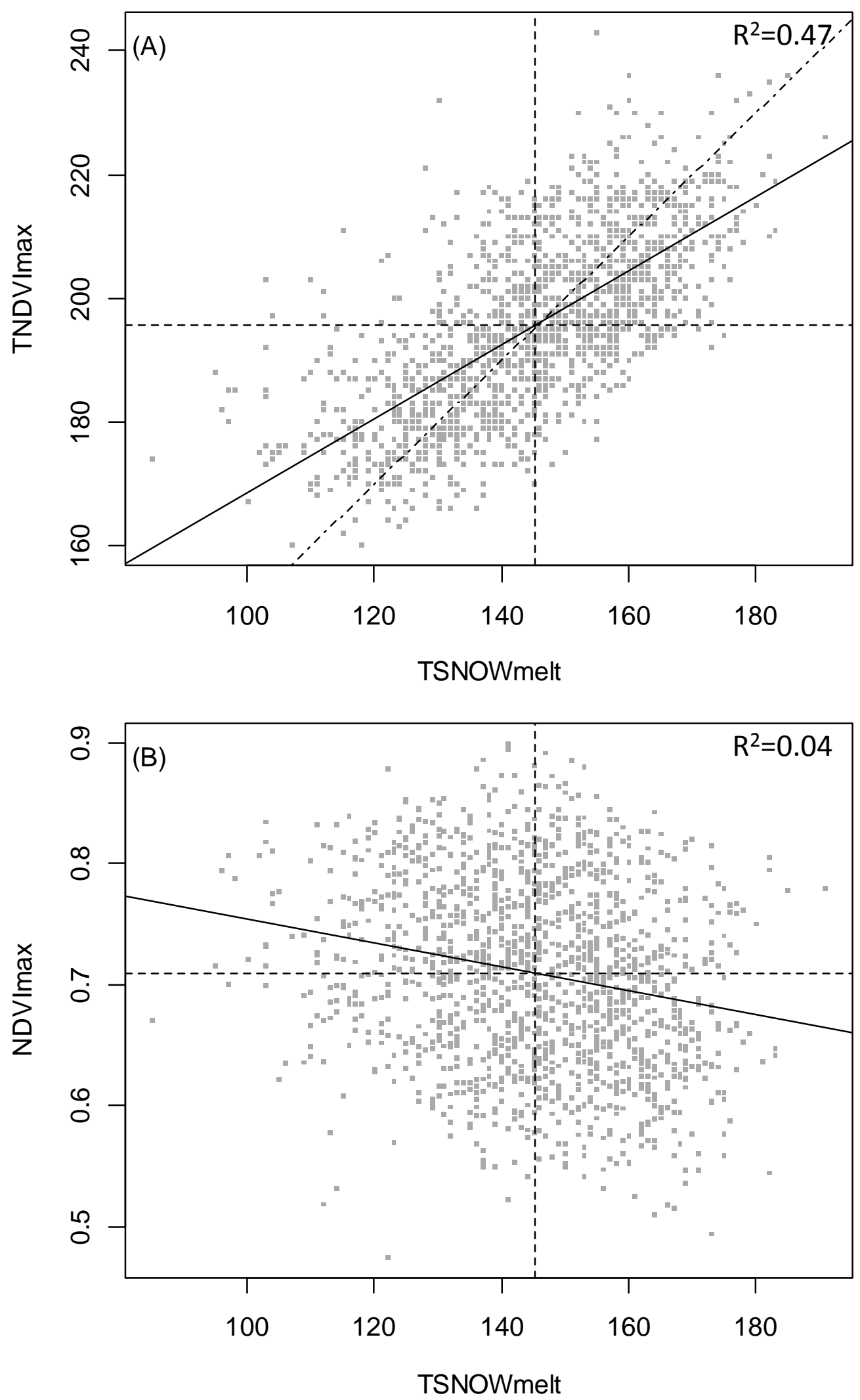

Supplementary Figure 1 